\title{
Discussion: Engineering the UK Motorway System 1950-2000
}

\author{
R. J. Bridle and J. Porter
}

\section{J. N. Benjafield MSc, (Transportation) C Eng MICE} I was surprised that although the authors made extensive reference to earthwork and pavement problems associated with the Preston by-pass there was no reference to the largely successful train-laid concrete pavements for the M1 in Hertfordshire opened in 1960 and no comparison of the economy and performance of concrete, including continuously reinforced concrete pavement, pavements versus asphalt pavements.

Another problem which beset early planners and engineers was the (in)accuracy of forecast traffic flows and their heavy vehicle content. Much larger vehicle flows than anticipated required a lot of four-lane motorways to be widened to six lanes and the much greater heavy vehicle flows resulted in early pavement failures. I know of a case in relation to parts of the M63 where pavement design was initially based on 15\% heavy vehicles in accordance with Department of Environment design memoranda pertaining at the time (mid-1970s) but had to be completely amended in the light of the up to 35\% heavy vehicle flows actually occurring on much of the adjacent network then open.

Fifty years ago, the Greater London Plan envisaged five major ring roads around London: A, B, C (effectively the north and south circular roads), D (now the M25), and E (about 30 miles out). Only the M25 is fully constructed plus some portions of some of the others. What about the remainder?

Can the authors please comment on these matters?

\section{Authors' reply}

We are grateful to Mr Benjafield for his comments. The paper is essentially a synopsis of a very much longer volume published by Thomas Telford on behalf of the Motorway Archive Trust. It is Volume 2 The Frontiers of Knowledge and Practice. ${ }^{1}$

The paper could not deal with every topic covered in Volume 2 and Mr Benjafield's reference to the lengths of concrete pavements on the M1 is useful. Concrete pavements were not wholly competitive and only represent $10-15 \%$ of the pavement stock. They have proved in greater need of maintenance and a number of sections have been dug up. Nevertheless, from the early days the argument was that they provided competition for black top. There was also a perceived need to maintain expertise and a share of the market to enable specialist manufacturers to invest in state of the art equipment. Sir William Harris, the then Director General of Highways, pondered the need for subsidising concrete pavements taking note of the fact that they were designed for a 40-year life as against 20 years for black top. However, subsidy proved unnecessary and concrete pavements continued to win an acceptable share of the market despite some prejudice against them.

In Volume 2, John Cox, formerly Managing Director of Tarmac National Construction, provides a contractor's view of the qualities of both concrete and black top pavements, while Ian Lake and Maurice Maggs, both formerly head of Engineering Intelligence Division, reflect on the competition between black top and concrete and the role of the Ministry of Transport in ensuring a level playing field while taking account of the need to foster the development of a healthy and competitive road construction industry.

We refer to the percentage of Heavy Goods Vehicles (HGVs) attracted to motorways, particularly in relation to the effect it had on the loading of long span bridges. At the beginning of the motorway programme forecasting was crude and the handed-down wisdom was that the percentage of HGVs in the flow at opening would be 15\%. By contrast, the Midlands Regional Strategic Traffic Model (MRSTM) indicated that the flow on the Midland Links when fully opened would be in excess of 30\% - this forecast proved remarkably accurate when the roads opened and observations showed 32\% HGVs in the traffic. The consequences for pavements designed before then were significant and many sections required reconstruction much earlier than expected.

In the Bridges chapter of Volume 2 we deal with the dilution of loading on long span bridges due to the inclusion of private vehicles in the stream of HGVs. While the Severn Bridge was designed for $4.5 \mathrm{kN}$ per lane metre, calculations taking a random selection of vehicles from a representative population produced a distribution curve the ten percentile of which showed a loading of $9 \mathrm{kN}$ per lane metre (not 97 as in the paper). Later, observations were to show that the traffic flow was not random and convoy behaviour put the ten percentile at $12 \mathrm{kN}$ per lane metre.

The last paragraph of Mr Benjafield's contribution raises an important issue. Since the demise of the motorway programme 
and the abandonment of the 'Forecast and Provide Policy' the alternative has been, virtually, a 'zero build' strategy, the M6 toll road being an exception. The consequence is evident in growing inter-urban congestion. Currently the pendulum appears to be swinging towards a capital programme of some kind for inter-urban roads. Widening seems a favourite choice, but widening is expensive and disruptive, delivering the benefits of decongestion to the widened road but nowhere else. For wholly new routes the benefits of redistribution and reassignment accrue and they can divert traffic from existing overloaded roads. In this context it is possible to cite route E simply for inter-urban traffic with less frequent interchanges than M25, which carries a proportion of on-off intra-urban trips. By contrast, inner routes would be aimed at intra-urban distribution. A clear cut case for a new route would be an improved trunk road between Strensham and Solihull, which could remove much of the SW-NE traffic from the M5/M42 with massive economic benefit.

Hopefully, the debate for new inter-urban routes will get into gear soon and avoid the propagandised sound bites that have plagued the transport debate thus far.

\section{REFERENCE}

1. BRIDLE R. and PORTER J. (eds) The motorway achievement Vol. 2: Frontiers of knowledge and practice. Thomas Telford, London, 2002. 